\title{
Changes in soil deformation and shear strength by internal erosion
}

\author{
C. Chen \& L. M. Zhang \\ The Hong Kong University of Science and Technology, Hong Kong, China \\ D. S. Chang \\ AECOM Asia Company Ltd., Hong Kong, China
}

\begin{abstract}
Internal erosion is a major cause for failures and incidents in slopes, embankment dams, landslide dams and dikes. After the loss of some fine particles, the microstructure and mechanical behaviour of the soil change. In this study, a series of tests was conducted on a gap-graded soil using salt to replace part of soil particles to investigate soil deformations and shear strength changes caused by the loss of a predefined amount of fine particles. The dissolution of predefined amounts of salt in the soil specimen during saturation process successfully simulated different degrees of erosion. Drained triaxial compression tests were performed on the samples already subject to internal erosion to study the changes in the mechanical behaviour of the soil. After loss of a significant amount of fine particles, the void ratio became larger, the critical state line rose substantially, the soil behaviour became less dilative, and the shear strength decreased significantly.
\end{abstract}

\section{INTRODUCTION}

Suffusion involves selective erosion of fine particles within the matrix of coarse soil particles under seepage flow (Chang \& Zhang 2013a). It occurs when certain geometric criteria and hydraulic criteria are met (e.g. ICOLD 2012, Chang \& Zhang 2013a). After losing soil particles during erosion process, the contacts between soil particles and soil fabric may change, which will induce significant settlement, a coarser and more permeable structure, and a higher possibility of slope instability or even failure of the structure (Wan \& Fell 2008, Ke \& Takahashi 2015, Chang \& Zhang 2013a).

Most of the previous studies simulated the internal erosion process by controlling the hydraulic gradient. For instance, Chang \& Zhang (2014) studied the stress-strain behaviour of a gap-graded soil subject to internal erosion under various stress states. When the applied hydraulic gradient reached 8.5 , the cumulative loss of fine particles ranged from $2.5 \%$ to $5 \%$ of the total soil mass, and the initially strainsoftening behaviour of the test soil became strain hardening as shown in Fig. 1. Xiao \& Shwiyhat (2012) applied a downward hydraulic gradient of 20.8 to induce seepage and erosion of soils, and examined the shear strength of the soils through consolidated- undrained tests. Ke \& Takahashi (2012) conducted a series of seepage tests on cohesionless soils by applying different hydraulic gradients to cause internal erosion. They found that a soil sample containing $25 \%$ of fines lost $9.8 \%$ and $11.1 \%$ of par- ticles by total mass under maximum imposed hydraulic gradients of 0.45 and 0.51 , respectively.

The amount of loss of fine particles is hard to control in a gradient-controlled test as it is highly dependent on the grain-size distribution, applied hydraulic gradient and stress state (Bendahmane et al. 2008). In this research, another method, which uses salt to replace some soil particles to achieve designed large degrees of erosion, is adopted.

The main objectives of this research are to study the deformation of soils induced by loss of fine particles and the subsequent stress-strain behaviour of the soils.

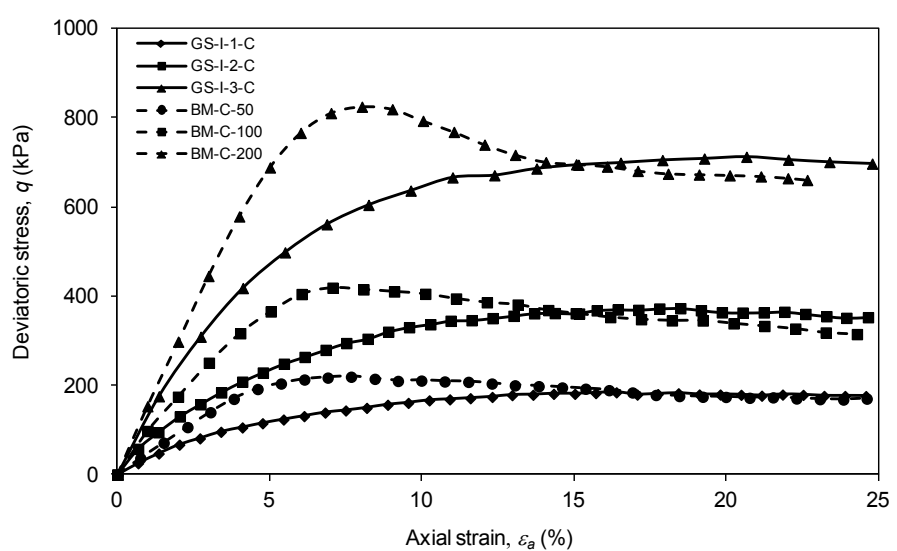

Figure 1. Stress-strain relationships through triaxial compression tests without and with internal erosion under different initial isotropic stress conditions. 


\section{TESTING APPARATUS}

The experimental setup consists of a triaxial system, a water supply and collection system, and a data collection system as shown in Fig. 2.

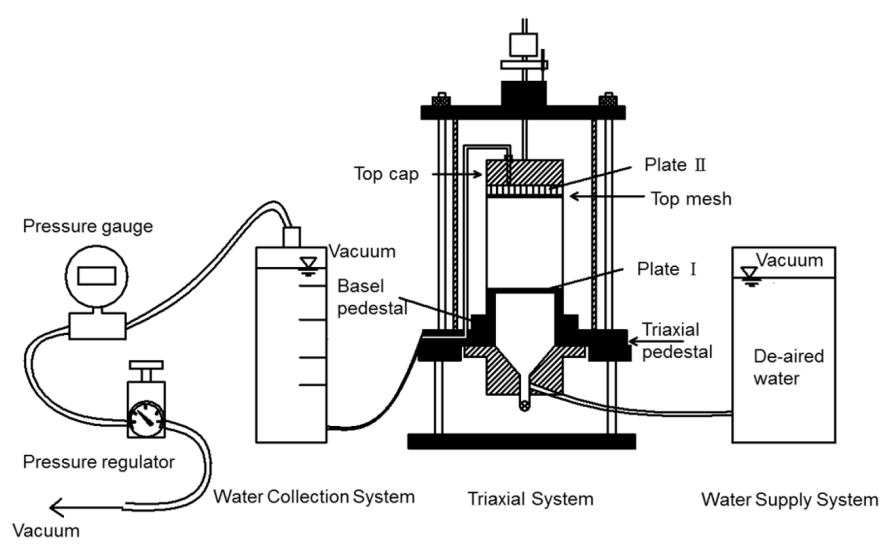

Figure 2. Experimental setup.

\subsection{Triaxial system}

The computer-controlled triaxial apparatus was used to apply a designed stress state to the soil, lead seepage flow through the soil sample and conduct compression tests on the soil. A hollow base pedestal is designed for the de-aired water to flow uniformly from the bottom to top of the sample. Two perforated plates (plates I and II) with a hole diameter of 1 $\mathrm{mm}$ are used to support the specimen and allow the water or solution to flow in and out uniformly.

\subsection{Water supply and collection system}

The water supply system uses a transparent acrylic water tank to supply de-aired water while the water collection system is a vacuum system that provides a pressure difference between the water supply system and the collection system to maintain a constant water flow across the sample during saturation. A pressure regulator is connected to the water collection cylinder to adjust the vacuum and maintain a constant water head difference between the upstream and downstream water levels. The precision of the pressure gauge is $0.05 \mathrm{kPa}$; thus the hydraulic gradient can be changed at an increment of 0.033 for a soil sample $150 \mathrm{~mm}$ in height.

\subsection{Data collection system}

The deformations induced by internal erosion are captured using a photographic method. The total vertical displacement of the specimen during shearing is measured using a linear variable differential transformer (LVDT) with a precision of $0.02 \mathrm{~mm}$. Photos are taken with a fixed measuring distance and a fixed camera angle. The horizontal and vertical displacements of the soil sample can be obtained by conversion distances on photos using vertical and horizontal scale factors.

\section{TESTING MATERIAL AND SAMPLE PREPARATION}

\subsection{Texting material}

The soil in this research was a type of poorly graded sand obtained by separating different sizes of completely decomposed granite particles according to the designated grain size distribution curves (Fig. 3, 0\% salt). Based on the extended internal stability criteria for gap-graded soils (Chang \& Zhang 2013b), test specimens containing $20 \%$ of fine particles with a gap ratio of 7.87 can be defined as internal unstable, which has a high potential to lose its fine fraction under seepage. The soil particles in the grain size range of $0.09-0.15 \mathrm{~mm}$ are termed "fine particles", which differ from the term "fines' that is smaller than $0.075 \mathrm{~mm}$ (ASTM 2012). All the specimens contained $20 \%$ of fine particles by weight, and $5 \%$, $10 \%, 15 \%$ of the total mass were replaced by salt (Table 1).

Table 1. Test ID and Designated Erosion Rates.

\begin{tabular}{lcc}
\hline Test ID & Fine content (\%) & Erosion rate* $(\%)$ \\
\hline A1 & 20 & 0 \\
A2 & 20 & 5 \\
A3 & 20 & 10 \\
A4 & 20 & 15 \\
\hline
\end{tabular}

* Erosion rate: Percent of particles replaced by salt.

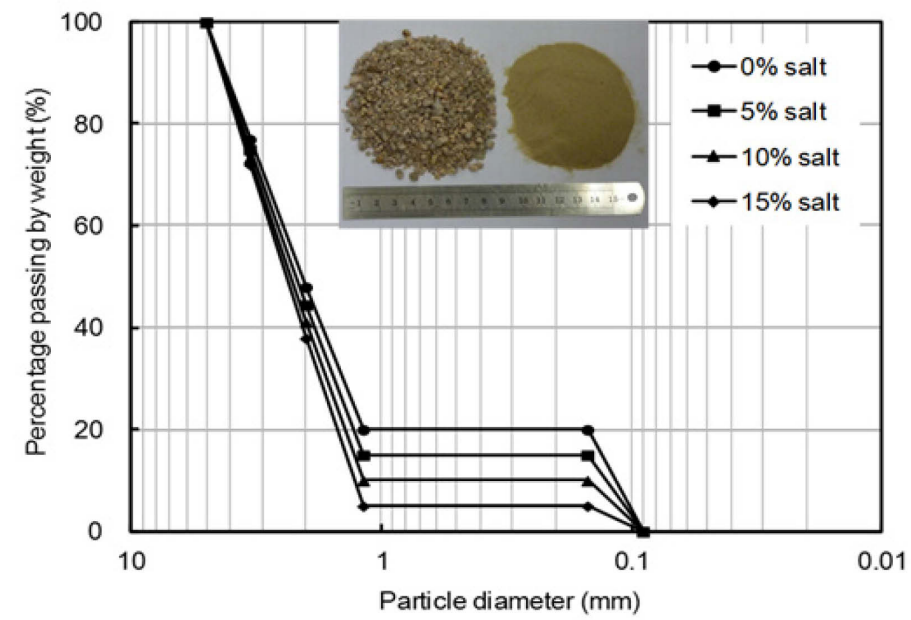

Figure 3. Grain size distributions of soils after internal erosion.

\subsection{Sample preparation}

Standard soil compaction test was conducted to find the optimal water content (i.e. 5.5\%) and the maximum dry density (i.e. $1787 \mathrm{~kg} / \mathrm{m}^{3}$ ) of test soil (Fig. 4). Each sample for erosion and triaxial tests was 76 $\mathrm{mm}$ in diameter and $150 \mathrm{~mm}$ in height, and prepared by moist tamping to prevent soil segregation. The salt was added into the soil and uniformly mixed before compaction. The mixed soil was then statically compacted in ten layers using the procedure proposed by Ladd (1978) to the desired dry density at a rate of $1.25 \mathrm{~mm} / \mathrm{min}$. 


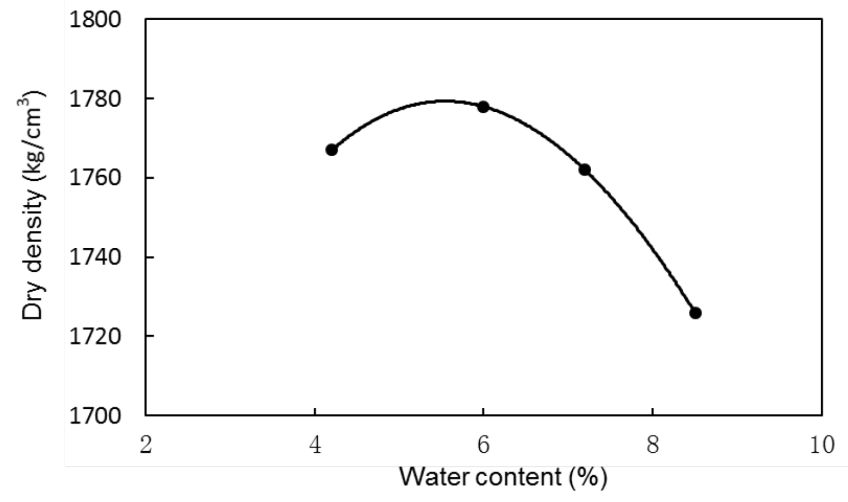

Figure 4. Dry density against water content.

\section{TESTING PROCEDURE}

After consolidation under an isotropic confining pressure of $50 \mathrm{kPa}$, soil saturation was performed in three steps: carbon dioxide, de-aired water and back pressure saturation. The salt was dissolved by introducing de-aired water and the inflow hydraulic gradient was controlled at a very small value (i.e. 0.1) for a sufficiently long time (i.e. 36 hours) to guarantee a uniform and homogeneous saturation process. De-aired water saturation would stop when no salt from the outflow water precipitated when tested in an oven. Then, back-pressure saturation began and lasted four hours. The B-value was checked to measure the degree of saturation. Photos were taken before and after the internal erosion process to measure the deformations caused by internal erosion. In the future soil deformations should be continuously monitored in the saturation process.

Drained shearing tests were finally conducted at an axial strain rate of $0.05 \% /$ minute to investigate the stress-strain behaviour of the soil subjected to internal erosion with the loss of different amounts of fine particles. The test was started at an isotropic confining stress of $50 \mathrm{kPa}$ and the confining stress for all the tests was kept constant (i.e. $50 \mathrm{kPa}$ ) while the axial stress was increased gradually.

\section{EXPERIMENTAL RESULTS}

\subsection{Erosion-induced deformation and void ratio change}

The relations between the strains and the loss of fine particles are shown in Fig. 5. With increasing loss of fine particles, the contacts between soil particles decreased and the force chains in the soil may collapse due to lack of lateral support from the fine particles, leading to substantial axial, radial and volumetric strains. During static compaction, an anisotropic contact network developed, with the contacts in the horizontal direction being smaller. Accordingly, the radial strain was greater than the axial strain when

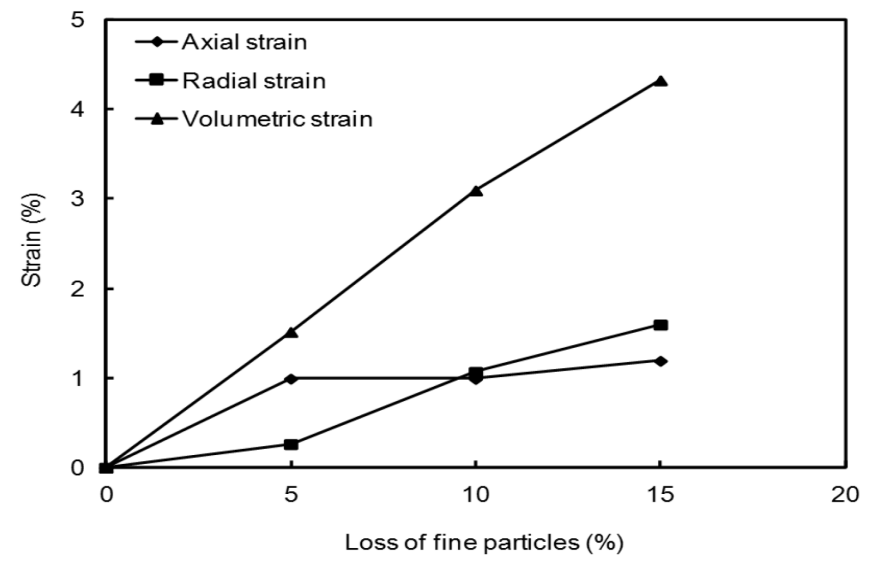

Figure 5. Deformations of the soil specimens caused by loss of fine particles.

the soil was subject to internal erosion under an isotropic stress condition.

Moreover, the maximum erosion-induced volumetric strain (i.e. $4.4 \%$ ) and axial strain (i.e. $1.19 \%$ ) of the test soil (A4) are much larger than the maximum wetting-induced volumetric strain (i.e. $-0.47 \%$, negative sign represents increase of soil volume) and axial strain (i.e. $0.09 \%$ ) of the soil (Zhao \& Zhang 2014). Therefore, the wetting deformation of the sample without salt can be ignored for simplicity.

The void ratio of the specimen during the internal erosion process can be calculated based on the measured deformations and the mass of the eroded soil. Although the volume of the specimen decreased during the internal erosion process, the void ratio of the soil still increased as the loss of fine particles outweighed the decrease in the soil volume. With the loss of fine particles, the mass fraction of the coarse particles increased (Fig. 3), which would result a looser and coarser soil structure. Figure 6 shows the increase of void ratio with increasing eroded fine particles at the end of the internal erosion test. The initial void ratio of all the soil samples were 0.461 , while at the end of the internal erosion test, the maximum final void ratio reached 0.644 (A4), with an increment of $40 \%$.

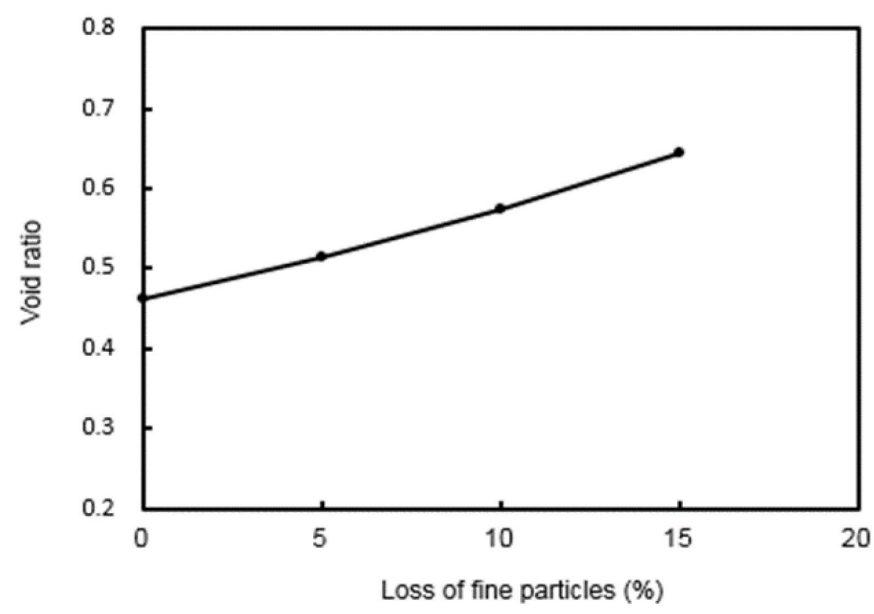

Figure 6. Increase of void ratio due to internal erosion. 


\subsection{Changes in mechanical behaviour of soil after erosion}

Figure 7 presents the stress-strain relationships of the test soils after losing different amounts of fine particles. The soil without erosion (A1 in Table 1) shows apparent strain softening and dilative behaviour. When a certain amount of fine particles is lost, the soil strength decreases and the dilation tendency becomes weaker.
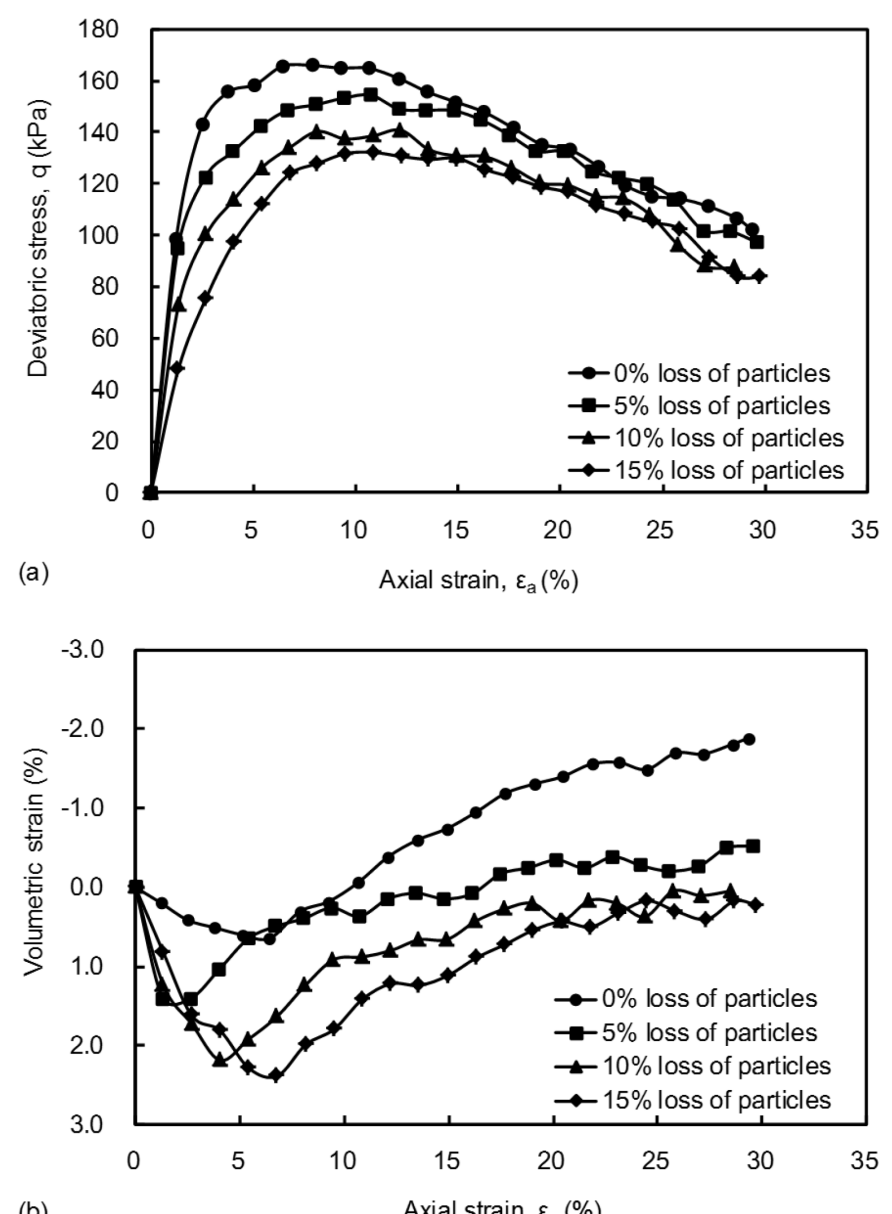

(b)

Axial strain, $\varepsilon_{\mathrm{a}}(\%)$

Figure 7. Evolution of the stress-strain relationships with the loss of fine particles: (a) deviatoric stress versus axial strain; (b) volumetric strain versus axial strain.

By controlling the hydraulic gradient, the amounts of eroded soil particles under the isotropic stress condition are limited to a small range. The fine particles filling the large pores formed by the coarse particles have a high potential to erode. As long as the skeleton structure formed by the coarse particles remains stable, the void ratio will increase and a looser soil structure will develop as the infill particles erode. The shear behaviour of the soil will change from the dilative before internal erosion to the contractive after internal erosion (Fig. 1). By using salt to replace a large percentage of soil particles, both the infill particles that do not support the force chains and the fine particles that support the stability of the force chains disappear, causing the collapse and re-compaction of the soil structure. The soil par- ticles will rearrange and form a stable soil packing after erosion. Therefore, in this study, the soils after subject to internal erosion exhibit weaker but still strain softening behaviour.

The critical state was considered to be reached at the end of the tests (when $\varepsilon_{\mathrm{a}}=30 \%$ ) as the rate of increase of volumetric strain apparently decreased. The four soil samples at the end of internal erosion are different soils with different grain-size distributions (Fig. 3). As the critical state line for each test soil could not be obtained from a single shearing test, a slope of the critical state lines of 0.034 is adopted for further analysis, which was obtained from tests on the same type of soil by Zhao \& Zhang (2013). Fig. 8 shows the stress states of the soils during shearing and the interpreted critical state lines. The internal erosion increases the void ratio of the soil, so the critical void ratio increases with increasing loss of fine particles. The state parameter can be used to explain the stress-strain behaviour by accounting for both void ratio and stress level. Dilation tendency is apparent for negative state parameter values, and contractive tendency for positive state parameter values. Figure 8 shows that the initial states of all the samples are located below their respective critical state lines, which means that all the soil samples will exhibit dilative behaviour during shearing. With increasing amount of eroded fine particles, the state parameter becomes larger and the soil behaviour becomes more contractive. A smaller drop of post-peak shear resistance can be observed with the increasing loss of fine particles (Fig. 7).

Wood (2007) proposed a "grading state index" concept to characterize the relationship between changing grading and soil mechanical behaviour during erosion. The grading state index decreases with the loss of fine particles and the critical state line moves upward with increasing specific volume and decreasing grading state index. When erosion happens, some fine particles are removed; the void ratio increases and the grading state index falls, which indicates a rise of the critical state line. In Figure 8, an apparent trend of rising critical state line can be easily observed with increasing loss of soil particles, which is consistent with Wood's theory. From Figure 8 , the soils with a larger amount of eroded fine particles will have a larger void ratio after internal erosion, which is followed by a less strongly strain softening behaviour during shearing. This implies that the increase of soil void ratio after erosion is quicker than the upward movement of its critical state line, which indicates an increase of the state parameter. Thus the soil response will feel "looser".

Numerical analyses by Wood et al. (2010) also showed that a combination of material removal and skeleton compression will lead to an increase in specific volume and state parameter. The increase in the 
state parameter will consequently reduce the strength of soil, which corresponds well to the results from this experimental research. During the internal erosion process, a larger void ratio is generated by a larger loss of fine particles, which forms a relatively looser soil structure. With a loose soil packing, the contacts between particles are small and the interlocking between particles are weak, which will lead to a reduction in shear strength. Therefore, with the increasing amount of eroded fine particles, the strength of the soil matrix decreases and a decreasing trend in the peak strength of the specimen can be observed.

Figure 9 presents the changes in the peak friction angle and the critical-state friction angle with the loss of fine particles. Both the peak friction angle and the critical friction angle decrease with increasing amount of loss of fine particles. The peak friction angle goes down from $38.7^{\circ}$ (A1) to $34.6^{\circ}$ (A4), which decreases by $11 \%$, while the critical friction angle decreases by $10 \%$ from $30^{\circ}$ (A1) to $27^{\circ}$ (A4).

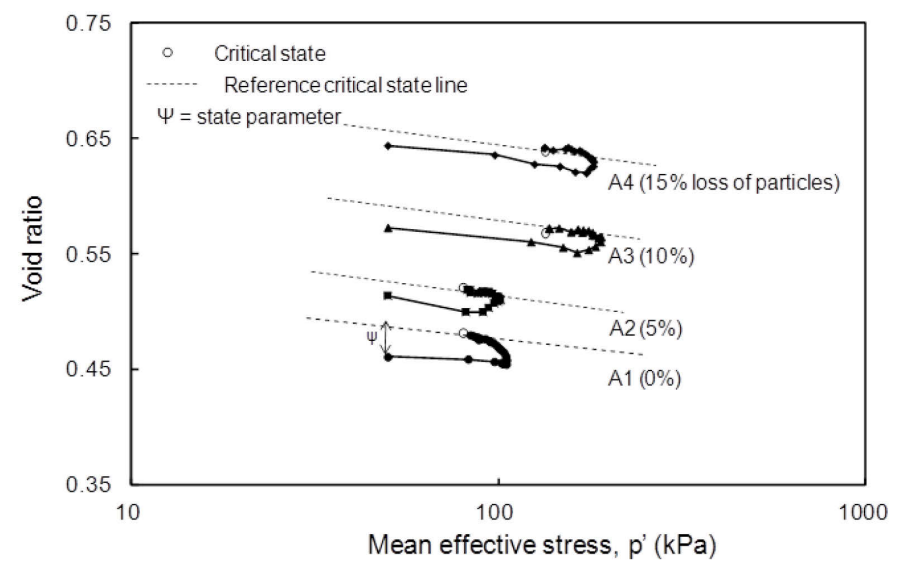

Figure 8. State parameter of test soils.

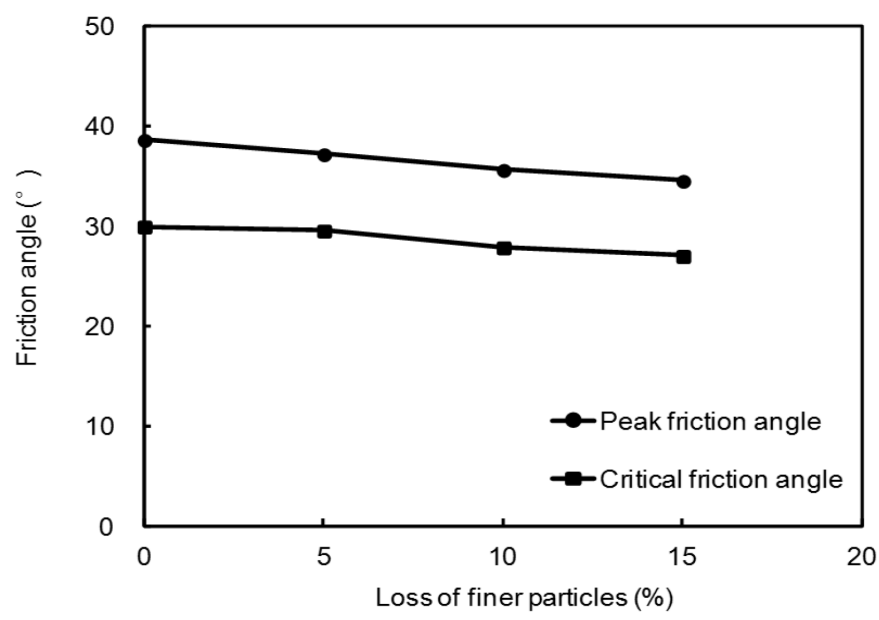

Figure 9. Variation of the peak and critical friction angle of the test soils with the loss of different amounts of fine particles.

\section{CONCLUSIONS}

A series of experiments was conducted on a gapgraded soil to investigate soil deformations caused by internal erosion and the influence of an extremely large loss of fine particles on the stress-strain behaviour of soils subjected to internal erosion. The following conclusions can be drawn based on the experimental study:

(1) With the increasing loss of fine particles, both the soil mass and soil volume decrease but the net effect is the increase of the void ratio. The soil becoming looser as the fine particles erode. Substantial axial strain, radial strain and volumetric strain develop during the internal erosion process.

(2) During the drained triaxial shearing test, the soils with a smaller loss of fine particles showed a more dilative response. The shear strength decreases with the increasing amount of eroded fine particles. The peak friction angle decreases by $11 \%$ from $38.7^{\circ}$ to $34.6^{\circ}$ as $15 \%$ of particles by weight are lost. The critical friction angle also decrease, but to a lesser degree.

(3) The state parameter increases and the critical state line rises with the loss of increasing amount of fine particles, which indicates a more contractive tendency.

\section{ACKNOWLEDGEMENTS}

This research was substantially supported by the Construction Industry Council Hong Kong (Grant No. CIC15EG02) and the Research Grants Council of the Hong Kong SAR (Grant No. C6012-15G).

\section{REFERENCES}

ASTM 2012. Standard practice for classification of soils for engineering purposes (unified soil classification system). D2487, West Conshohocken, PA.

Bendahmane, F., Marot, D. \& Alexis, A. 2008. Experimental parametric study of suffusion and backward erosion. Journal of Geotechnical and Geoenvironmental Engineering 134(1): 57-67.

Chang, D.S. \& Zhang, L.M. 2013a. Critical hydraulic gradients of internal erosion under complex stress states. Journal of Geotechnical and Geoenvironmental Engineering 139(9): 1454-1467.

Chang, D.S. \& Zhang, L.M. 2013b. Extended internal stability criteria for soils under seepage. Soils and Foundations, 53(8): 569-583.

Chang, D.S., Zhang, L.M. \& Cheuk, Johnny. 2014. Mechanical consequences of internal soil erosion. HKIE Transactions 21(4): 1-11.

ICOLD 2012. Internal erosion of existing dams, levees and dikes, and their foundations. Bulletin No. 1XX, Vol. 1, International Commission on Large Dams, Paris, France.

Ke, L. \& Takahashi, A. 2012. Strength reduction of cohesionless soil due to internal erosion induced by one-dimensional 
upward seepage flow. Soils and Foundations 52(4): 698711.

Ke, L. \& Takahashi, A. 2015. Drained monotonic responses of suffusional cohesionless soils. Journal of Geotechnical and Geoenvironmental Engineering 141(8): 04015033.

Ladd, R.S. 1978. Preparing test specimens using undercompaction. Geotechnical Testing Journal 1(1): 16-23.

Wan, C.F. \& Fell, R. 2008. Assessing the potential of internal instability and suffusion in embankment dams and their foundations. Journal of Geotechnical and Geoenvironmental Engineering 134(3): 401-407.

Wood, D.M. 2007. The magic of sands. Canadian Geotechnical Journal 44(11), 1329-1350.

Wood, D.M, Maeda, K. \& Nukudani, E. 2010. Modelling mechanical consequences of erosion. Geotechnique 60(6), 447457.

Xiao, M. \& Shwiyhat, N. 2012. Experimental investigation of the effects of suffusion on physical and geomechanic characteristics of sandy soils. Geotechnical Testing Journal 35(6): 890-900.

Zhao, H.F., Zhang, L.M. \& Chang, D.S. 2013. Behaviour of coarse widely graded soils under low confining pressures. Journal of Geotechnical and Geoenvironmental Engineering 139(1): 35-48.

Zhao, H.F. \& Zhang. L.M. 2014. Instability of saturated and unsaturated coarse granular soils. Journal of Geotechnical and Geoenvironmental Engineering 140(1): 25-35. 